\title{
Gênero e sexualidade: estamos no canto do ringue?
}

\author{
- ADRIANA ViANNA \\ Museu Nacional, Universidade Federal do Rio de Janeiro, Rio de \\ Janeiro, Rio de Janeiro, Brasil \\ Maria Elvira Benítez \\ Museu Nacional, Universidade Federal do Rio de Janeiro, Rio de \\ Janeiro, Rio de Janeiro, Brasil
}

DOI: $10.11606 /$ issn.2316-9133.v25i25p36-41

Escrever sobre o panorama atual das políticas envolvendo gênero e sexualidade leva-nos a estados de espírito muito diversos: ora ficamos próximas à melancolia e ao desânimo profundo, ora nos alentamos com a certeza de que processos e atores que já foram postos em marcha não recuarão tão facilmente. Recentemente, em uma atividade promovida pelos alunos do programa de pós-graduação do qual ambas somos professoras, Maria Elvira Díaz Benítez valeu-se da metáfora do boxe para tratar dos golpes e contragolpes que têm sido desferidos nos últimos tempos na seara dos direitos e políticas envolvendo gênero e sexualidade. Dando seguimento a isso, indagamo-nos: em que ponto da batalha ou em que lugar do ringue se encontram as diferentes perspectivas sobre gênero e sexualidade no cenário político em que vivemos?

$\mathrm{Na}$ impossibilidade de tratar exaustivamente todas as temáticas referentes a gênero e sexualidade nos limites deste texto, pretendemos enfatizar dois feixes principais: direitos LGBT e aborto, destacando também a relevância das formas de se evocar gênero e família nos debates recentes. Se todo sexo é político, como já afirmava Gayle Rubin décadas atrás, cada vez mais nos parece que é através das falas inflamadas sobre ou a partir dele que se alinham e antagonizam muitos dos protagonistas políticos do atual cenário.

De modo geral, podemos pensar que estamos acompanhando - e participando de - um momento que em parte desdobra e em parte antagoniza o processo político que tem na Constituição Federal de 1988 seu marco principal. Resultado e ao mesmo tempo peça-chave do processo de redemocratização política, a Constituição de 1988 cristalizou a entrada da sexualidade e da reprodução como campos legítimos para exercício e disputa de direitos no Brasil. ${ }^{1} \mathrm{Se}$, em alguns casos, como na defesa da equidade de gênero e na proibição da discriminação por gênero e raça, vemos a manifestação da força de movimentos sociais já atu-

${ }^{1}$ Para um quadro mais detalhado, ver Carrara \& Vianna (2008) 
antes desde os anos 1970, como o movimento negro e o movimento feminista, em outros casos, como a não inclusão da "orientação sexual" como motivo de discriminação a ser combatido, expressa-se quão negativa era a correlação de forças nesse campo específico.

Apesar da derrota sofrida pelo que era então conhecido como Movimento Homossexual Brasileiro, mudanças significativas aconteceram nas últimas décadas na seara dos chamados direitos LGBT. Como diversos trabalhos têm apontado, a reorganização dos atores políticos significativos nesse campo passa tanto por mudanças importantes na configuração dos movimentos sociais, inclusive com suas tensões internas, quanto por contextos nacionais e internacionais. Nunca é demais deixar sublinhado que os anos 1990 estiveram marcados simultaneamente pelo enfrentamento da epidemia de HIV/Aids, com as consequentes discussões políticas em torno do formato a ser assumido por esse enfrentamento, e pela emergência da gramática dos direitos sexuais e reprodutivos, especialmente a partir das grandes conferências no âmbito das Nações Unidas ocorridas no Cairo, em 1994, e em Beijing, em 1995. Em todos esses casos, o entrelaçamento entre a linguagem da saúde e dos direitos humanos foi crucial para redefinir gramáticas e repertórios de ação coletiva para diversos movimentos sociais e atores governamentais. ${ }^{2}$

Alguns marcos notáveis que podemos indicar nos últimos anos estiveram ligados a ações desenvolvidas no âmbito do Executivo ou a iniciativas que envolveram o Judiciário, sendo talvez a mais famosa dessas a decisão, em 2011, do Supremo Tribunal Federal no sentido de reconhecer a união estável para casais do mesmo sexo. Já no plano do Executivo, salvo tímidos registros anteriores, podemos considerar que é na virada dos anos 2000 que importantes cristalizações institucionais ocorrem, como a criação do Conselho Nacional de Combate à Discriminação (CNCD), ligado ao Ministério da Justiça, em 2001, e sua posterior transformação, em 2010, em Conselho Nacional de Combate à Discriminação e Promoção de Direitos LGBT. Indissociável dessa mudança foi a realização da 1ํㅡ Conferência Nacional de Gays, Lésbicas, Bissexuais, Travestis e Transexuais, em 2008, que contou com a presença do então presidente Lula. Ainda perseguindo a linguagem do boxe, podemos considerar essa conquista como um mata-cobra dos movimentos sociais, que abriu passo para a elaboração do Plano Nacional de Promoção de Cidadania e Direitos Humanos de Lésbicas, Gays, Bissexuais, Travestis e Transexuais, em 2009, e para uma segunda conferência em 2011.

Essa segunda conferência, de 2011, já não teve o mesmo tom de celebração, alegria e esperança da primeira, nem teve a presença da presidenta Dilma Rou-

\footnotetext{
${ }^{2}$ A literatura relevante sobre o tema pode ser considerada ampla hoje. Para ficarmos em algumas referências apenas, podemos mencionar: Vianna \& Lacerda (2004); Facchini (2005; 2009); Carrara \& Simões (2007) e Aguião (2014).
} 
sseff. ${ }^{3}$ Ao contrário, esteve marcada pela insatisfação dos movimentos sociais diante de perceptíveis retrocessos, sendo o principal deles a proibição da divulgação do chamado kit anti-homofobia, material educativo produzido a partir do acordo firmado, dentro do Programa Brasil sem Homofobia, com o Fundo Nacional de Desenvolvimento da Educação (FNDE) e que consistia na elaboração de material educativo a ser distribuído a instituições em todo o país. Prestes a ser divulgado, o material foi alvo de uma saraivada de golpes desferida por parlamentares e setores conservadores da sociedade civil que o tratavam de "kit gay" e, mobilizando, como usual, o tema da proteção das crianças e das famílias, alegavam que ele viria a "estimular promiscuidade e homossexualismo" em crianças e adolescentes. $\mathrm{O}$ recuo do governo frente a essa pressão consumou o soco no estômago dos movimentos LGBT, fazendo sangrar uma úlcera gástrica antiga que aos poucos começava a sarar.

O combate direto e agressivo observado nesse momento pode ser identificado em torno de outros projetos de lei, como o da criminalização da homofobia (PL 122/06) ou, vindo do lado oposto do ringue, o da "cura gay" (PL 24/11), evidenciando não apenas o quanto o legislativo é um terreno de difícil movimentação para aqueles e aquelas que querem a ampliação dos direitos relativos à diversidade sexual e de gênero, mas sua capacidade de atingir, por meio de diversas coligações e estratégias de pressão e barganha, também ao Executivo. Sem poder discorrer sobre esses processos em detalhe aqui, gostaríamos apenas de indicar alguns pontos que consideramos relevantes para o cenário atual tomando a "cura gay" como foco. Apresentado inicialmente pelo então deputado federal e presidente da Frente Parlamentar Evangélica João Campos (PSDB-GO), o Projeto de Decreto Legislativo (PDC 24/11) visando sustar os parágrafos que estabelecem as normas para atuação de psicólogos em situações relativas à orientação sexual foi aprovado em 2013 pela Comissão de Direitos Humanos e Minorias. Ainda que arquivado naquele mesmo ano, em 2015 foi reaberto sob a tutela do pastor e deputado federal Marco Feliciano (PSC-SP). Na audiência pública ocorrida em junho daquele ano, entre pastores, missionários, deputados, psicólogos e ativistas LGBTs, marcaram presença também pessoas que vieram dar depoimentos sobre como se curaram de sua homossexualidade através principalmente de conversão religiosa e apoio terapêutico.

Vemos aqui combinarem-se narrativas que tratam de pertencimentos religiosos, da natureza política e do papel do Estado, bem como de explicações sobre a própria sexualidade e sua mutabilidade. Longe, muito longe, de um combate unidimensional, o que percebemos no cenário contemporâneo é a mobilização de diferentes estratégias narrativas, de associação e de lobby político e também

\footnotetext{
${ }^{3}$ Uma excelente análise das conferências e do quadro das políticas LGBTs no período pode ser encontrada no já mencionado trabalho de Silvia Aguião (2014). Para o papel dos conselhos e as vicissitudes do modelo de participação, ver Aguião, Vianna \& Gutterres (2014).
} 
de embate moral estabelecidas em diálogo com a linguagem dos direitos humanos (ou com uma apropriação desta) para definir modos de gestão do gênero e da sexualidade. ${ }^{4}$ Acompanhando os argumentos de artigo recente de Sergio Carrara, podemos afirmar que estamos diante de um momento em que se torna especialmente visível a coexistência, mais que a sucessão, de diferentes regimes de regulação da sexualidade. Para usar os termos do autor, ao se articularem, colidirem ou se enfrentarem, tais regimes vão, desenhando "diferentes políticas sexuais e estilos de regulação moral" (CARRARA, 2015).

A linguagem dos direitos ou, mais especificamente, dos direitos à vida, também tem sido mobilizada há muitos anos para manter ou mesmo estender o cerceamento à autonomia das mulheres em relação às decisões reprodutivas, sobretudo no caso do aborto. Se, como apontamos no começo deste texto, no cenário da constituinte a presença feminista organizada teve papel significativo, sendo responsável por inscrições significativas no texto legal e, mais tarde, por importantes ganhos institucionais, sobretudo a partir da criação da Secretaria Especial de Políticas para as Mulheres (SPM), em 2003, o aborto permanece como ponto especialmente sensível de disputas políticas, chegando a protagonizar algumas viradas políticas bastante marcantes.

Como indica Lia Zanotta Machado em artigos recentes, ${ }^{5}$ a relação entre o governo Lula e a SPM possibilitou uma estrutura e articulação de enorme envergadura que viabilizou adesões estaduais e municipais aos pactos nacionais, como o Pacto do Enfrentamento à Violência e o Pacto da Redução da Mortalidade Materna, assim como a aprovação da lei de enfrentamento à violência doméstica contra as mulheres, em 2006, conhecida como Lei Maria da Penha. Esse é, sem dúvida, um dos melhores swings dados pelos movimentos sociais feministas. Se, em certo momento, porém, parecia que esse esforço conjugado atingiria um dos centros nervosos da regulação dos corpos femininos, o aborto, com a possibilidade de apresentação de uma minuta de projeto de lei para legalizar a interrupção da gravidez à Comissão de Seguridade Social e Família da Câmara dos Deputados, a conjuntura turbulenta do chamado "escândalo do Mensalão" transformou o projeto em moeda de troca com importantes atores políticos, como a Conferência Nacional dos Bispos do Brasil (CNBB) e outros segmentos conservadores.

Em outubro de 2005, por sua vez, foi registrada a primeira "Frente Parla-

\footnotetext{
${ }^{4}$ Em dissertação de mestrado sobre a atuação desses grupos, Alexandre Gonçalves (2015) mapeou 19 organizações vinculadas ao Éxodus e ao GAAP divididas em 6 escolas de capacitação, 10 igrejas e 3 ministérios. Uma questão muito interessante que ressalta o autor em sua análise é o quanto os discursos construídos por esses reformistas combinam não apenas narrativas religiosas que fazem alusão ao pecado, mas narrativas políticas (no sentido de ponderar quais práticas devem ou não serem reconhecidas pelo Estado) e narrativas científicas, ou seja, homossexualidade como distúrbio psicológico com uma origem clara que pode ser combatida.

${ }^{5}$ Ver Machado (2016).
} 
mentar em defesa da vida contra o aborto", e, com a legislatura que entrou em vigor recentemente, formou-se também a "Frente Parlamentar a favor da Família". Para 2015, encontramos registradas, ainda, a "Frente Parlamentar Mista da Família e Apoio à Vida" e a "Frente Parlamentar em Defesa da Vida e da Família”. Assim, podemos ver como a Comissão de Seguridade Social e Família passou a ser cobiçada pela bancada evangélica multipartidária, criada em setembro de 2003, que reúne deputados de diferentes ordens. Um dos pontos fortes desse processo de disputas palmo a palmo no ringue dos direitos reprodutivos foi protagonizado por ninguém mais, ninguém menos que o deputado Eduardo Cunha, através da apresentação do PL 5069/2013 que pretende modificar a Lei $12845 / 13$, alterando as condições para oferecimento da profilaxia da gravidez nos casos das vítimas de violência sexual.

Essa iniciativa, longe de ser fato isolado, está indiscutivelmente entrelaçada tanto ao fortalecimento de agendas e coligações terrivelmente conservadoras do ponto de vista dos direitos sexuais e reprodutivos quanto às articulações para destituição do segundo governo da presidenta Dilma Rousseff, incluindo-se aí a alteração significativa do papel e lugar das instituições governamentais ligadas às questões de gênero e sexualidade. Como aponta estudo recente realizado por Flavia Biroli sobre a discussão do aborto na Câmara dos Deputados, ${ }^{6}$ estamos diante de ofensivas que clamam por "menos Estado" no que diz respeito ao desejo de reduzir direitos sociais e políticas públicas, e "mais Estado" no que tange ao controle dos corpos de mulheres, pessoas LGBTs, ativistas sociais e todos "os indesejáveis" que devem ser cada vez mais criminalizados e encarcerados. A evocação constante do tópos da família - como bem a ser valorizado - e do gênero - como ideologia perniciosa a ser combatida - não se faz inocentemente nesse cenário. Não se trata, como nunca se tratou, de "uma família” ou de algo estável e facilmente definível como "gênero", mas de encarniçados combates através e por dentro das definições desses termos e dos corpos e almas que os habitam. Não nos esqueçamos de que depois do projeto de lei apresentado pelo deputado agora cassado Eduardo Cunha, muitos outros capítulos vieram, inclusive a chamada "Primavera Feminista", que pode ser vista talvez como uma verdadeira invasão insurreta do ringue masculino e heteronormativo por aquelas que não pretendem ficar na plateia enquanto seus corpos e vidas estão sob ataque. Se o boxe é afinal uma boa metáfora, não sabemos. Mas que quatro cordas são pouco para definir todos os terrenos onde as lutas continuarão se dando, temos certeza.

\section{Referências bibliográficas}

${ }^{6}$ BIROLI, Flavia. Aborto em debate na Câmara dos Deputados. IPAS/CFEMEA/Observatório de Sexualidade e Política, 2016. 
AGUIÃO, Silvia. Fazer-se no "Estado": uma etnografia sobre o processo de constituição dos "LGBT" como sujeitos de direitos no Brasil contemporâneo. Tese (Doutorado) - Programa de Doutorado em Ciências Sociais, Instituto de Filosofia e Ciências Humanas. Universidade Estadual de Campinas, Campinas, 2014.

AGUIÃO, Silvia; VIANNA, Adriana; GUTTERRES, Anelise. Limites, espaços e estratégias de participação do Movimento LGBT nas políticas governamentais. In: LEITE LOPES, José Sérgio; HEREDIA, Beatriz. (Orgs.). Movimentos sociais e esfera pública: o mundo da participação. Rio de Janeiro: CBAE, 2014.

CARRARA, Sergio. Moralidades, racionalidades e políticas sexuais no Brasil contemporâneo. Mana, 21(2), 2015, p. 323-45.

CARRARA, Sergio; SIMÕES, Julio. Sexualidade, cultura e política: a trajetória da identidade homossexual masculina na antropologia brasileira. Cadernos Pagu, Campinas, n. 28, p. 65-100, 2007.

CARRARA, Sergio; VIANNA, Adriana. Os direitos sexuais e reprodutivos no Brasil a partir da "Constituição Cidadã". In: OLIVEN, Ruben George; RIDENTI, Marcelo; BRANDÃO, Gildo Marçal (Orgs.). A Constituição de 1988 na vida brasileira. São Paulo: Hucitec, 2008. p. 334-59.

FACCHINI, Regina. Sopa de letrinhas? Movimento homossexual e produção de identidades coletivas nos anos 90. Rio de Janeiro: Garamond, 2005.

FACCHINI, Regina: Entre compassos e descompassos: um olhar para o campo e para a arena do movimento LGBT brasileiro. Bagoas, Natal, n. 4, 2009.

GONÇALVES, Alexandre Oviedo. Flexibilizando estéticas, restringindo sexualidades: disputas de agentes pela demarcação do religioso. Dissertação (Mestrado) - Programa de Pós-Graduação em Antropologia Social, Faculdade de Filosofia, Letras e Ciências Humanas, Universidade de São Paulo, São Paulo, 2015.

MACHADO, Lia Z. Interfaces e deslocamentos: feminismos, direitos, sexualidades e antropologia. Cadernos Pagu, v. 1 (42), p. 13-46, 2014. E

Feminismos brasileiros nas relações com o Estado. Contextos e incertezas. Cadernos Pagu, v. 1 (47), 2016.

VIANNA, Adriana; LACERDA, Paula. Direitos e politicas sexuais no Brasil: o panorama atual. Rio de Janeiro: Clam/IMS/Cepesq, 2004.

\section{autores Adriana Vianna}

Professora do PPGAS/Museu Nacional/UFRJ.

\section{Maria Elvira Benítez}

Professora do PPGAS/Museu Nacional/UFRJ. 


\section{O golpe nosso de cada dia: as mui familiares ameaças aos direitos dos povos indígenas no contexto do impeachment}

L Bruno Martins Morais

Universidade de São Paulo, São Paulo, São Paulo, Brasil

DOI 10.11606/issn.2316-9133.v25i25p42-45

Não havia menção à Funai na medida provisória que reorganizou a Esplanada dos Ministérios logo no primeiro dia em que Temer assumiu a Presidência, ainda como interino. Uma comitiva de lideranças indígenas foi bater à porta do recém-empossado ministro da Justiça, Alexandre de Moraes, e ouviu um pedido de desculpas: seria "mero erro de redação". Mas corria na imprensa a notícia de que a Casa Civil concentraria os órgãos da política fundiária - o governo havia recuado, portanto? ${ }^{1}$ A imprensa alardeava que as demarcações realizadas ao final do governo Dilma seriam anuladas, Alexandre de Moraes negou peremptoriamente - o governo havia recuado, portanto ${ }^{2}$

A política indigenista de Temer parece estar sendo desenrolada no improviso, ou na maldade. ${ }^{3}$ Em que pese a negativa do ministro, em dezembro do ano passado (2016) foram devolvidos à Funai pelo menos vinte procedimentos de terras que aguardavam portarias declaratórias e decretos de homologação. Na mesma época, a Folha de S.Paulo publicou uma minuta de decreto com um novo marco regulatório do procedimento de demarcação de terras indígenas, incluindo como regra a tese do marco temporal: apenas as áreas efetivamente ocupadas na data de promulgação da Constituição, 5 de outubro de 1988, seri-

\footnotetext{
${ }^{1}$ Com efeito, cinco pastas responsáveis pelas políticas de reforma agrária do governo federal, entre as quais a Secretaria Especial de Agricultura Familiar e do Desenvolvimento Agrário, foram transferidas para a Casa Civil já em maio. Cf. Temer transfere Incra e secretarias da reforma agrária para a Casa Civil. Portal G1, 30 mai. 2016. Disponível em: <http://g1.globo. com/politica/noticia/2016/05/temer-transfere-incra-e-secretarias-da-reforma-agraria-paracasa-civil.html>. Acesso em: 28 fev. 2017.

${ }^{2}$ Temer diz a ruralistas que vai revisar desapropriações e demarcações. O Globo, 30 abr. 2016. Disponível em: <http://oglobo.globo.com/brasil/2016/04/30/3046-temer-diz-ruralistas-quevai-revisar-desapropriacoes-demarcacoes $>$. Acesso em: 18 fev. 2017.

3 "Maldade" e "improviso" são palavras de Adriana Ramos, coordenadora do Programa de Política e Direito Socioambiental, em análise publicada pelo El País. Cf. Entre o improviso e a maldade: a política (anti-)indigenista do Governo Temer. El País, 24 jan. 2017. Disponível em: <http://brasil.elpais.com/brasil/2017/01/24/opinion/1485269600_994030.html>. Acesso em: 28 fev. 2017.
} 
am passíveis de ser demarcadas. ${ }^{4} \mathrm{~A}$ aplicação da tese, tal qual, anularia $80 \%$ dos procedimentos demarcatórios em aberto no país, sobretudo fora da Amazônia, onde a expansão do agronegócio expropriou as terras dos índios entre a década de 1940 e 1980 . O ministro, no entanto, veio novamente a público negar que havia qualquer disposição do governo em alterar o decreto $n^{\circ}$ 1775/96.

E novamente, apesar da negativa, em janeiro deste ano (2017) foi publicada uma portaria que criava um "Grupo Técnico Especializado" com poderes para reavaliar os processos de demarcação em andamento e observar o "cumprimento da Jurisprudência do Supremo Tribunal Federal". ${ }^{5}$ A portaria poderia produzir os mesmos efeitos que uma mudança no procedimento demarcatório via decreto e teria a vantagem de aparentar constitucionalidade. Reações do movimento indígena, indigenista e do Ministério Público Federal parecem ter surtido efeito: o dispositivo foi substituído no dia seguinte por um texto mais enxuto, reduzindo as atribuições do grupo técnico - improviso ou maldade? ${ }^{6}$

Na mesma edição que publicava a portaria, o Diário Oficial da União trazia a nominação à presidência da Funai de Antonio Fernandes Toninho Costa, um dentista e pastor evangélico indicado pelo Partido Socialista Cristão (PSC). Desde o segundo semestre do ano passado, pelo menos três pessoas já haviam anunciado publicamente a sua indicação à presidência do órgão. Entre as especulações, a de maior corpo era a de dois generais; mas a nomeação de um militar à chefia da Funai cheirava demasiado à ditadura para que passasse desapercebido ao movimento indígena. Pressão contra o Ministério da Justiça resultou na recusa em militarizar a presidência, mas não impediu que o Gen. Franklinberg fosse nomeado diretor de promoção ao desenvolvimento sustentável, a pasta que tem competência sobre o licenciamento ambiental. Desse modo, a esplanada garantiu controle militar sobre a incidência do órgão em obras de impacto. ${ }^{7}$

Já Toninho Costa inaugurou seu mandato em turnê ao Mato Grosso do Sul. Reuniu-se com representantes das federações agropecuárias, sentou com usinei-

\footnotetext{
${ }^{4}$ Documento do governo altera regra para demarcar terra indígena. Folha de S.Paulo, 12 dez. 2016. Disponível em: <http://www1.folha.uol.com.br/poder/2016/12/1840543-documentodo-governo-altera-regra-para-demarcar-terra-indigena.shtml>. Acesso em: 19 fev. 2017.

${ }^{5}$ Ministro da Justiça altera demarcação de terras indígenas no país. Folha de S.Paulo, 18 jan. 2017. Disponível em: <http://www1.folha.uol.com.br/poder/2017/01/1851036-ministro-da-justicaaltera-demarcacao-de-terras-indigenas-no-pais.shtml>. Acesso em: 19 fev. 2017.

${ }^{6}$ Ministro revoga própria norma sobre demarcação de terras indígenas. Folha de S.Paulo, 19 jan. 2017. Disponível em: <http://www1.folha.uol.com.br/poder/2017/01/1851456-ministrorevoga-propria-norma-sobre-demarcacao-de-terras-indigenas.shtml>. Acesso em: 19 fev. 2017. ${ }^{7}$ Em tempo, após uma queda de braço com o então Ministro da Justiça Omar Serraglio (PMDB), Antonio Toninho Costa foi demitido em maio de 2017 e, na imprensa, acusou a ingerência da bancada ruralista no órgão. Cf. Deixo a Funai por não ceder a ingerências políticas, diz Toninho Costa. Valor Econômico, 05 maio 2017. Disponível em: <http://www.valor.com.br/ politica/4958910/deixo-funai-por-nao-ceder-ingerencias-politicas-diz-toninho-costa>. Acesso em: 05 jul. 2017. Em seu lugar, como presidente da Fundação, foi finalmente nomeado o Gen. Franklimberg Ribeiro de Freitas.
} 
ros e defendeu a criação de um fundo que viabilizasse as demarcações com indenização aos pretensos proprietários de títulos incidentes sobre terras indígenas. Em entrevista, criticou o assistencialismo da fundação: "temos que produzir sustentabilidade", disse, sem explicar como pretende "ensinar os índios a pescar" (!) diante da redução radical do orçamento da instituição. ${ }^{8}$ A ONG Survival International publicou nota em dezembro de 2016 acusando a previsão orçamentária da fundação para o ano de 2017 de estar defasada em catorze anos. ${ }^{9}$

O governo improvisa ou malfaz as politicagens de corredor. $\mathrm{O}$ futuro da instituição, do marco legal do procedimento demarcatório, do indigenato, enfim, seguem incertos mas mal-agourados. Por sobre tudo isso, uma Comissão Parlamentar de Inquérito supostamente implantada para investigar irregularidades na demarcação de terras indígenas e quilombolas pela Funai e Incra, respectivamente, encerrou os seus trabalhos recomendando o indiciamento de 67 pessoas. Entre elas, lideranças comunitárias acusadas de falsidade ideológica por identificarem-se como indígenas ou quilombolas; antropólogos e indigenistas, acusados de forjarem os relatórios de identificação e delimitação de terras; e mesmo acadêmicos, pesquisadores da Universidade Federal de Santa Catarina e do Museu Nacional, associados à associação da classe. Medidas judiciais estão sendo preparadas na tentativa de evitar que essas pessoas respondam acusações criminais pela prática do ofício antropológico; ou, pior, por sua identidade étnica.

O sentimento geral é de derrota. Não creio que haja entre nós, a essa altura, alguém que não se sinta como se tivesse perdido algo. Talvez a inocência. Talvez a esperança. Esse sentimento não deixa dúvidas de que o impedimento da presidenta eleita bambeou a corda da democracia - por que, então, os espectros que rondam o pós-golpe nos são, assim, tão familiares? A enumerar: a fragilidade da Funai; a carência de perspectivas no andamento das demarcações; os discursos defendendo mudanças no procedimento demarcatório; as minutas de decreto; os avanços no Legislativo e no Judiciário das teses mais conservadoras e contrárias ao indigenato, enfim, todas essas mais sérias ameaças aos direitos dos povos indígenas no contexto do golpe chegaram à esplanada e assentaram nos corredores dos ministérios, do Congresso Nacional, durante a democracia do Partido dos Trabalhadores (PT). A mesma democracia que agora impera defender?

O "golpe", penso, é uma oportunidade para autocrítica. No momento em que a estimativa de propina envolvida na construção da hidrelétrica de Belo Monte bate à casa dos 120 milhões de reais, já não creio que haja muito a ser dito sobre a política dos últimos dez anos: capitulamos, mediamos, compusemos, e de al-

\footnotetext{
${ }^{8}$ Nova Funai quer índios produtivos. Valor Econômico, 13 fev. 2017. Disponível em: <http://www. valor.com.br/brasil/4866768/nova-funai-quer-indios-produtivos>. Acesso em: 18 fev. 2017.

${ }^{9}$ Corte de orçamento na Funai pode ameaçar tribos isoladas, diz ONG. Portal G1. Disponível em: <http://g1.globo.com/ac/acre/noticia/2016/12/corte-de-orcamento-na-funai-pode-ameacartribos-isoladas-diz-ong.html>. Acesso em: 18 fev. 2017.
} 
gum modo somos também responsáveis por as coisas haverem chegado aonde estão. Importante é lembrar, contudo, que houve nesse tempo os que fincaram o pé no chão. Por ora, Michel Temer ensaia, mas ainda não mostrou a que veio na política indigenista. Os ventos do impeachment parecem ter reanimado os tratores do progresso; e os custos sociais, sabemos, pagam primeiro os índios, os que fincam o pé no chão.

Apesar desses pesares, os Guarani têm o que comemorar neste começo de ano: no dia 27 de janeiro de 2017 foi publicada a identificação da TI Pindoty/ Araçá-Mirim (SP), a primeira delimitação de terra ratificada por um presidente da Funai indicado por Michel Temer. ${ }^{10} \mathrm{~A}$ escola da última década parece, em alguma medida, tê-los preparado para o golpe nosso de cada dia.

Nós, sim, é que ainda temos muito o que aprender com eles.

autor Bruno Martins Morais

Advogado e Mestre em Antropologia Social pelo PPGAS/USP. Assessor jurídico do Centro de Trabalho Indigenista e da Comissão Guarani Yvyrupa.

Recebido em 20/02/2017 Aceito para publicação em 20/02/2017

\footnotetext{
${ }^{10}$ Terra Guarani é identificada pela Funai. Instituto Socioambiental, 27 jan. 2017. Disponível em: <https://www.socioambiental.org/pt-br/noticias-socioambientais/terra-guarani-eidentificada-pela-funai>. Acesso em: 18 fev. 2017.
} 